\title{
Detection of damaged urban areas using interferometric SAR coherence change with PALSAR-2
}

\author{
Manabu Watanabe ${ }^{1,2^{*}}$, Rajesh Bahadur Thapa' ${ }^{1}$ Tsuneo Ohsumi ${ }^{3}$, Hiroyuki Fujiwara ${ }^{3}$, Chinatsu Yonezawa ${ }^{4}$, \\ Naoya Tomii ${ }^{5}$ and Sinichi Suzuki ${ }^{1}$
}

\begin{abstract}
The interferometric SAR coherence-change technique with coherence filter and polarization (HH and HV) has been used to detect the parts of buildings damaged by the 2015 Gorkha Earthquake. A survey of the building damage was conducted in every house to evaluate the detection accuracy in the Khokana and Sankhu urban areas in the Kathmandu Valley of Nepal. The damaged parts of the urban area were adequately detected using coherence-change $(\Delta \gamma)$ values obtained before the earthquake $\left(\gamma_{\text {pre }}\right)$ and during the inter-seismic stage of the earthquake $\left(\gamma_{\text {int }}\right)$. The use of a coherence filter effectively increased overall accuracy by $\sim 2.1$ to $7.0 \%$ with $\mathrm{HH}$ polarization. The incorporation of HV polarization marginally increased the accuracy ( 0.9 to $1.2 \%$ ). It was confirmed that road damage due to liquefaction was also observed using the interferometric SAR coherence-change detection technique. The classification accuracy was lower (27.1-35.1\%) for areas that were damaged. However, higher accuracy (97.8-99.2\%) was achieved for areas that were damage-free, in $\Delta y$ obtained from $\mathrm{HH}$ and $\mathrm{HV}$ polarization with a coherence filter. This helped to identify the damaged urban areas (using this technique) immediately after occurrence of an earthquake event.
\end{abstract}

Keywords: Disaster, Earthquake, Polarization, Building damage, Kathmandu

\section{Introduction}

In the aftermath of massive disasters affecting buildings, there is a demand for immediate detection of severely damaged urban areas. A high-resolution optical image sensor on board a satellite is one of the possible tools to meet this demand. However, cloud-free conditions over land occurred in only $22 \%$ of images from a dataset of weather observations from 5400 land stations worldwide (Warren and Eastman 2007), and such data for night time are unavailable. In contrast, synthetic aperture radar (SAR) observations are available for all weather conditions, day and night, and are an effective tool for detecting areas damaged in a disaster. The most popular application of SAR for a disaster is to estimate crustal movement during earthquakes and volcanic activity. The wide range of crustal movement induced by the

\footnotetext{
*Correspondence: 16hz001@ms.dendai.ac.jp

1 JAXA/EORC, 2-1-1 Sengen, Tsukuba, Ibaraki 305-8505, Japan Full list of author information is available at the end of the article
}

2015 Gorkha Earthquake was quickly examined with PALSAR-2 (phased array type L-band synthetic aperture radar 2)/ScanSAR mode) (Natsuaki et al. 2016; Kobayashi et al. 2015). The effective detection of urban areas damaged in 2011 off the Pacific Coast of Tohoku by the earthquake-induced tsunami was demonstrated using full polarimetry data obtained with the Japanese L-band SAR satellite, PALSAR (Watanabe et al. 2012). The polarimetric coherence between RR polarization and LL polarization $\left(\gamma_{\mathrm{RR}-\mathrm{LL}}\right)$ obtained before and after the disaster aided in effective detection. Coherence indicates the degree of similarity between a pair of images. Their conclusion also states that the main radar scattering mechanism for areas with collapsed buildings was surface scattering with high entropy. In several other papers, workers suggested use of the full polarimetry data to detect building damage (Chen and Sato 2013; Li et al. 2012). While the full polarimetry mode includes a lot of information, there are fewer opportunities for observation than with other single/dual polarization modes. This often results 
in no full polarimetric observation before the disaster, which is essential for detecting the damaged urban areas accurately.

Interferometric SAR coherence-change analysis obtained with single polarization has also been used to detect damaged urban areas. Yonezawa and Takeuchi (2001) used coherence obtained between a data pair including the 1995 Hyogoken-nanbu earthquake and a pair before the earthquake to show that the decrease in interferometric coherence was a good representative of the damaged urban area.

Tamura and El-Gharbawi (2015) have used coherence change to detect areas damaged in Ishinomaki City due to the 2011 earthquake off the Pacific Coast of Tohoku and the subsequent tsunami. They demonstrated that the coherence change reflected the degree of urban damage. Kobayashi et al. (2011) applied this technique to detect liquefaction areas associated with the 2011 Tohoku earthquake, and it displayed a good correlation between the liquefaction area and decrease in coherence.

The backscattering $\left(\sigma^{0}\right)$ properties of damaged urban areas were examined by Matsuoka and Yamazaki (2004). Coherence- and $\sigma^{0}$-based analyses were compared by Arciniegas et al. (2007) with ENVISAT/A-SAR data. The overall accuracy for detecting damaged urban areas from the change in coherence was $44.5 \%$, better than the one based upon absolute change of $\sigma^{0}(41.2 \%)$.

This paper highlights the interferometric SAR coherence-change technique and its use in the detection of urban areas damaged by the 2015 Gorkha Earthquake. New points in this paper include:

1. Use of a coherence filter to increase detection accuracy for damage-free areas.

2. A wide area, including areas of urban damage, agricultural area, and forest area, was used to evaluate the effectiveness of a coherence filter to pick up damaged urban areas.

3. $\mathrm{HV}$ as well as $\mathrm{HH}$ polarization was used to increase the accuracy of detection of damaged areas.

4. The evaluation was done with the validation data obtained from building damage surveys in every house. EMS-98 (Masonry), which is widely used to evaluate building damage, was adopted to connect the parameters obtained from the satellite with building damage levels.

The coherence-change technique was selected, because the minimum, effective parameters should be selected to reduce the calculation time.

The purpose of this paper was to pick out damaged urban areas from wide-scale images, including agriculture and forest areas. This implies that the detection accuracy for damage-free areas, of which the size is generally larger than of the damaged urban areas, is important. However, the seasonal change in $\sigma^{0}$ is well known not only for agriculture area, but also for forest areas (Way et al. 1990). In addition to this, recent workers also pointed out that increased $\sigma^{0}$ is often induced by rainfall (Lucas et al. 2010, Watanabe et al. 2015). To avoid these uncertainties, only the coherence parameters were used in this paper.

\section{Field data collection}

The Gorkha Earthquake occurred on April 25, 2015, with a moment magnitude of 7.8 and hypocenter at $28.231^{\circ}$ $\mathrm{N}, 84.731^{\circ} \mathrm{E}$, and depth of $8.2 \mathrm{~km}$ (US Geological Survey 2015). A quasi-vertical displacement estimated by combining the ascending and the descending data shows that the uplift area was distributed in the southern region, and the maximum displacement of $\sim 1.5 \mathrm{~m}$ was estimated around $20 \mathrm{~km}$ northeast from Kathmandu (Kobayashi et al. 2015).

Building damage surveys were conducted in every house in the Sankhu area on August 17 and 18 and in the Khokana area on August 19 and 20, 2015. The locations for the sites are overlaid on the interferometry image obtained with PALSAR-2 in Fig. 1 (image pair: February 21, 2015-May 2, 2015, Geospatial Information Authority of Japan 2015). Sankhu is located closer to the maximum uplift area, and Khokana is located in between. High-resolution imagery observed before the disaster on 12 March was obtained from Google Earth before the field survey. The imagery was used to identify a position for each building before the disaster. The damage level was estimated for each building, based on the European Macroseismic Scale (EMS-98, Grünthal 1998), which is widely used to evaluate building damage. This enabled

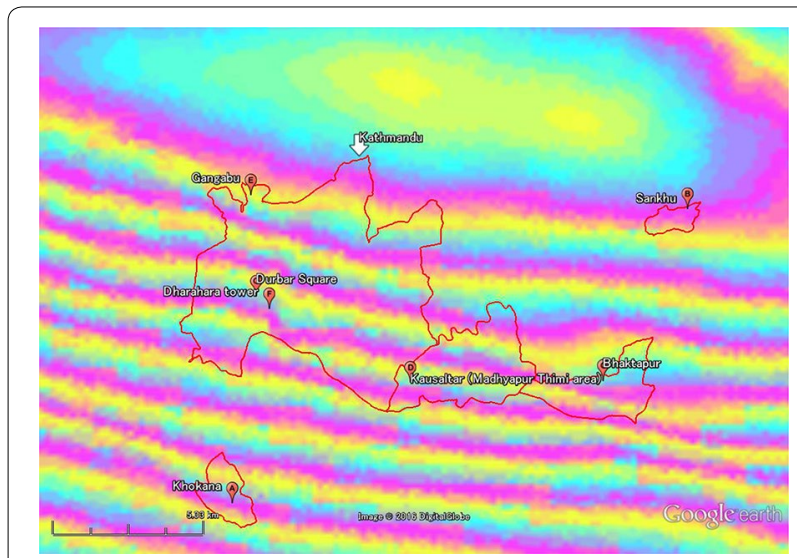

Fig. 1 Field experiment areas are overlaid on the interferometry image obtained with PALSAR-2 (image pair: February 21, 2015-May 2, 2015) 
us to connect the parameters obtained from the satellite with the levels of building damage. Grade 5 on the scale represents destruction, that is, total or near-total collapse of a building. Grade 4 represents very heavy damage, which includes half damage. There have been many cases of collapse of the upper stories of buildings, such that five-story buildings have been scaled down to second- or third-story buildings. Such cases were assigned to Grade 4. Grade 2 or 3 indicates partial damage. Details about the building damage surveys have been described by Ohsumi et al. (2016). Building damage surveys were also conducted in the areas, where the decrease in coherence was observed in Kathmandu, Bhaktapur, and Madhyapur Thimi; photographs and videos were taken.

A polygon for each house was produced based on a field experiment, and the damage level information was attached to each polygon. The polygons with same damage level were aggregated and were converted to raster data with 10-m resolution, which matched the PALSAR-2 processed data. The raster images for each damage level were aggregated. There were several pixels in which different damage levels were assigned in the same pixel. In that case, the damage levels were averaged. The range, 3.5 $\leq$ damaged level $<4.5$ was regarded as level $4 ; 4.5 \leq$ damaged level was regarded as level 5 .

\section{SAR data analysis}

The interferometric SAR coherence-change technique uses two $\gamma$ image pairs-one pair obtained (observed) before the disaster $\left(\gamma_{\text {pre }}\right)$ and another pair obtained during the inter-seismic stage of the disaster $\left(\gamma_{\text {int }}\right)$. Decrease in the coherence from the normalized coherence difference value can be calculated as follows.

$$
\Delta \gamma=\frac{\gamma_{\text {pre }}-\gamma_{\text {int }}}{\gamma_{\text {pre }}+\gamma_{\text {int }}}
$$

Larger $\Delta y$ indicates a larger decrease in coherence after a disaster.

The Japanese SAR satellite, ALOS-2 observed the Kathmandu area with dual polarization mode ( $\mathrm{HH}$ and $\mathrm{HV}$ ) and $10-\mathrm{m}$ resolution, before the disaster on October 4,
2014, and February 21, 2015, and after the disaster on May 2, 2015. From the data obtained before the disaster, $\gamma_{\text {pre }}$ was calculated for October 4, 2014, and February 21, 2015 , and $\gamma_{\text {int }}$ was calculated from the data obtained during the inter-seismic interval (February 21 and May 2, 2015). A medium filter with window size of 3 pixels was applied to reduce speckle noise, and $\Delta \gamma$ was calculated for each polarization $\left(\Delta \gamma_{\mathrm{HH}}, \Delta \gamma_{\mathrm{HV}}\right)$. The average of two polarizations $\left[\Delta \gamma_{(\mathrm{HH}, \mathrm{HV})}\right]$ was calculated to see how the utilization of dual polarization improved the detection accuracy.

Interferometric SAR coherence change with an additional filter was also tested to discriminate the damaged urban areas from forest stands, because higher coherence is expected to be observed for an urban area before the disaster. Figure 2 shows the normalized histogram for $\gamma_{(\mathrm{HH}, \mathrm{HV})}$ obtained before the disaster in the Khokana and Sankhu areas. Table 1 shows the average value of $\gamma$ for urban and other areas: $\gamma_{(\mathrm{HH}, \mathrm{HV})}$ for urban areas were $0.43-0.51$ and showed higher values than for other areas (0.32-0.35). These values depend on place, and a coherence filter with $\gamma_{\text {pre }}>0.5$ was selected for this time.

It takes $40 \mathrm{~min}$ to obtain one coherence image (single polarization, one pair) and takes $160 \mathrm{~min}$ for four coherence images (dual polarization, two pairs) with an Intel Xeon CPU E3 processor and 16 GB memory. It takes about $60 \mathrm{~min}$ to carry out the ortho-rectification. Total processing time from level 1.1 data is about $220 \mathrm{~min}$ with 10-m spatial resolution. Google Earth software was used to display the obtained image and compare those to the optical image.

\section{Results and discussion}

Figure 3a-d displays the PALSAR-2 magnitude image before (21 February) and after (2 May) the disaster, the magnitude difference, and Google Earth image. Many differences were observed in the magnitude image. The differences are due to change in soil moisture and change in the dielectric constant of trees (Watanabe et al. 2015). Severely damaged urban areas such as Sankhu, Khokana, and Bhaktapur do not show distinct differences in magnitude. Bright reflection from double-bounce scattering
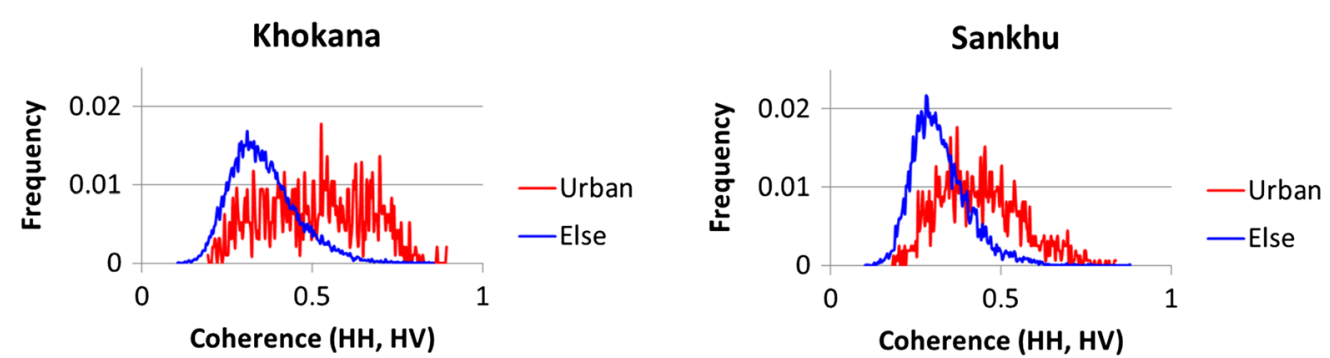

Fig. 2 Normalized histogram for $\gamma_{(\mathrm{HH}, \mathrm{HV})}$ obtained before the disaster in Khokana and Sankhu areas 
Table 1 Average value of $\gamma$ obtained before the disaster for urban and other areas in Khokana and Sankhu

\begin{tabular}{lll}
\hline & Khokana & Sankhu \\
\hline HH and HV & & \\
Urban & 0.51 & 0.43 \\
Other & 0.35 & 0.32 \\
HH & & \\
Urban & 0.52 & 0.44 \\
Other & 0.39 & 0.33 \\
HV & & \\
Urban & 0.49 & 0.43 \\
Other & 0.32 & 0.31 \\
\hline
\end{tabular}

was observed in urban areas before the disaster. Bright reflection from single- and/or double-bounce scattering is sometimes induced by debris (Watanabe et al. 2012). This may make it difficult to distinguish between damage-free urban areas before the disaster and damaged urban areas after the disaster.

Areas with $\Delta y_{\mathrm{HH}} \geq 0.2$ obtained near Kathmandu are represented in red in Fig. 3e. Outstanding decrease of $\gamma_{\mathrm{HH}}$ was observed for some areas including Sankhu, Khokana, and Bhaktapur. The decrease of $\gamma_{\mathrm{HH}}$ was also observed for forest and agriculture areas. This made it difficult to pick up damaged urban areas from only the wide-range image. Figure 3f shows $\Delta y_{(\mathrm{HH}, \mathrm{HV})}$ obtained with a coherence filter near Kathmandu. The misclassification observed in the mountain forest area has been reduced to some degree, while the damaged urban area has been detected. Detectability of damaged urban area was better than for those using only the $\Delta y_{\mathrm{HH}}$.

\section{Sankhu and Khokana}

The magnified image in Fig. 3e, f near Sankhu and Khokana, and the Google Earth image, is presented in Figs. $4 \mathrm{a}-\mathrm{c}$ and $5 \mathrm{a}-\mathrm{c}$. The red color in Fig. $4 \mathrm{a}$, b looks blurry, because the medium filter was applied. Snow cover in Khokana and Sankhu is very rare, and no snow cover effect was expected to the coherence image. Building damage survey results for each house are also presented in Figs. 4d and 5d. The red polygons in Figs. 4 and 5 represent the municipality borders of Pukhulacchi and Khokana, respectively. The areas include forest, agricultural, and urban areas, as shown in Figs. $4 \mathrm{c}$ and $5 \mathrm{c}$. The damaged urban areas are well detected by $\Delta \gamma_{\mathrm{HH}}$. However, the coherence decrease was also observed in the forest and agriculture areas. This is because temporal decorrelation is larger for the forest, and seasonal change is larger for the agriculture area. On the other hand, the misclassification observed in the forest and the agricultural areas decreased for the $\Delta \gamma_{(\mathrm{HH}, \mathrm{HV})}$ with coherence filter (Figs. 4b, 5b).

User's and producer's accuracies (Story and Congalton 1986) are presented in Table 2. A coherence filter improved the overall accuracy by $7.0 \%$ (from 87.9 to $94.9 \%$ ) for Shanku and by $2.1 \%$ (95.0 to $97.1 \%$ ) for Khokana in the case of $\Delta \gamma_{\mathrm{HH}}$. This supports the visual interpretation result observed in Figs. $4 \mathrm{~b}$ and $5 \mathrm{~b}$. The improvement was due to the improvement of accuracy for the damage-free area. The average accuracies for the damage-free areas in $\Delta \gamma_{(\mathrm{HH}, \mathrm{HV})}$ are $99.2 \%$ in Khokana and $97.8 \%$ in Sankhu. This enabled us to identify the damaged urban areas, as shown in Figs. $4 \mathrm{~b}$ and $5 \mathrm{~b}$.

The overall accuracies obtained from $\Delta \gamma_{\mathrm{HV}}$ were $97.4 \%$ for Khokana and $94.6 \%$ for Sankhu. These are comparable with the accuracies obtained from $\Delta \gamma_{\mathrm{HH}}$, but the average accuracy for damaged areas in $\Delta \gamma_{\mathrm{HV}}$ for Sankhu was $24.2 \%$. This value is $6 \%$ lower than the one for $\Delta \gamma_{\mathrm{HH}}$ (30.2\%).

Combination of $\mathrm{HH}$ and $\mathrm{HV}$ polarization marginally improved the accuracy by $0.9 \%$ (from 94.9 to $95.8 \%$ ) for Sankhu and by 1.2 \% (from 97.1 to $98.3 \%$ ) for Khokana. The main radar scattering mechanism for urban areas is double-bounce scattering. Higher $\sigma_{\mathrm{HH}}^{0}$ and $\gamma_{\mathrm{HH}}$ are expected from the double-bounce scattering with orientation angle of $\sim 0^{\circ}$, and higher $\sigma_{\mathrm{HV}}^{0}$ and $\gamma_{\mathrm{HV}}$ are expected from orientation angles $>0^{\circ}$ (Kimura 2008). By incorporating HV polarization, the double-bounce scattering is taken into account, which may aid in improving the accuracy.

The dependency of the classification accuracy in Khokana, and Sankhu on the damage level, is presented in Table 3. Case (1) building damage level $\geq 0$ is regarded as a damaged area. Case (2) building damage level $\geq 4$ is regarded as a damaged area. Case (3) building damage level $=5$ is regarded as a damaged area. The accuracy for each case is examined with $\Delta \gamma_{(\mathrm{HH}, \mathrm{HV})} \geq 0.2$ (see italics figures in Table 3). The best result was for $50.3 \%$ in Khokana and for $35.0 \%$ in Sankhu (see bold italics figures in Table 3). This was the highest value achieved by the suggested method. These producer's accuracies are comparable to the $32 \%$ obtained by Arciniegas et al. (2007). The relatively lower accuracies for the detection of damaged urban areas are discussed in "Madhyapur Thimi and Gangabu" section. 

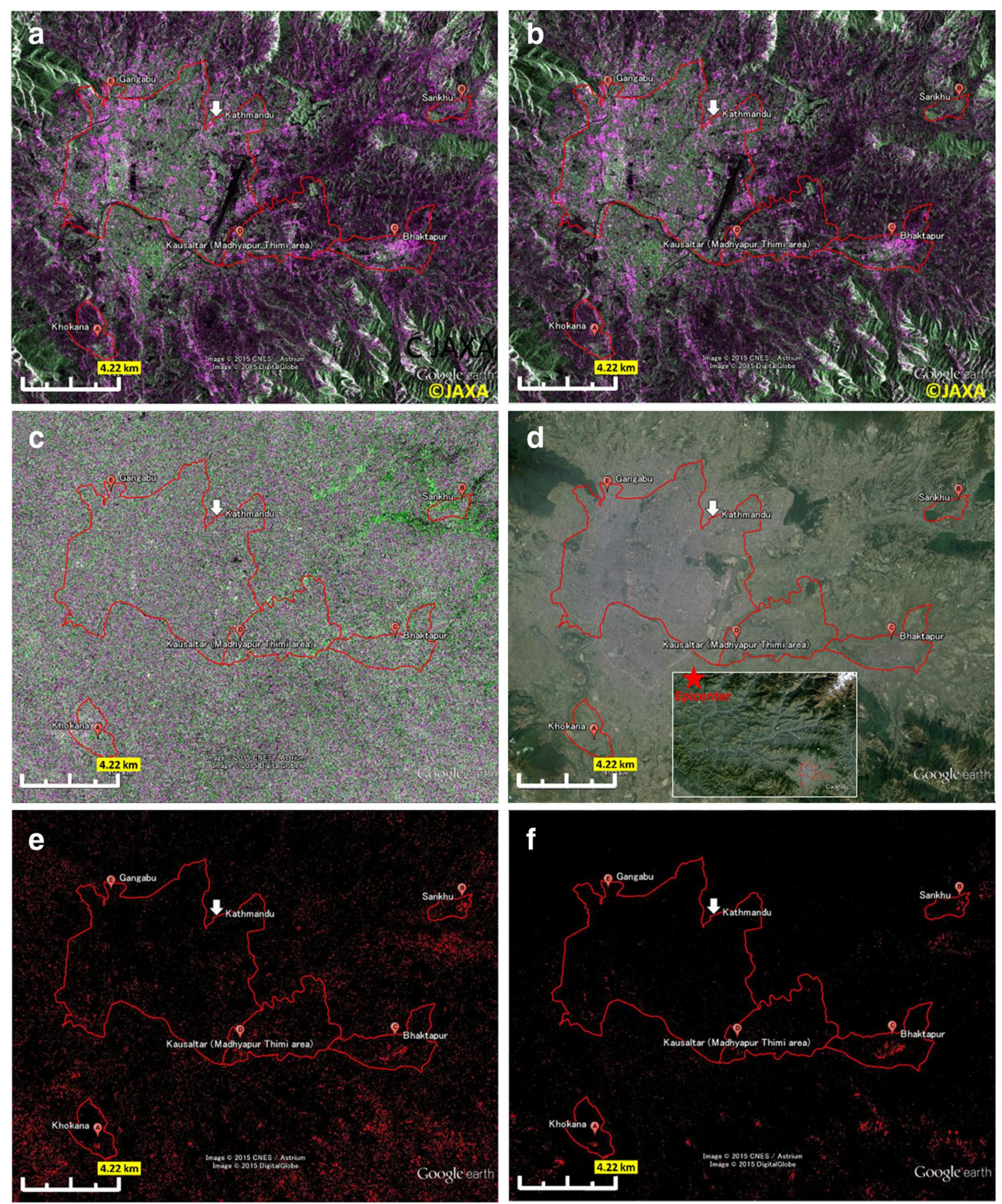

Fig. 3 a Magnitude image before the disaster (21 February). b Magnitude image after the disaster (2 May). c Difference between $\mathbf{a}$ and $\mathbf{b}$. d Google earth image. Smaller image shows position in epicenter and the target area. e Area with $\Delta \gamma_{\mathrm{HH}} \geq 0.2$ is represented in red. f Area with $\Delta \gamma_{(\mathrm{HH}, \mathrm{HV})} \geq 0.2$ and coherence filter is represented in red. Color legend for a-c: red and blue HH polarization, green HV polarization

Dependency of the classification accuracy on the $\Delta \gamma_{(\mathrm{HH}, \mathrm{HV})}$ threshold level is also presented in Table 3. The $\Delta y_{(\mathrm{HH}, \mathrm{HV})}$ threshold level is modified from 0.1 to
0.4 , and the classification accuracy was examined. With an increase in the $\Delta \gamma_{(\mathrm{HH}, \mathrm{HV})}$ threshold level, the average accuracy increased and saturated at around 0.3. However, 


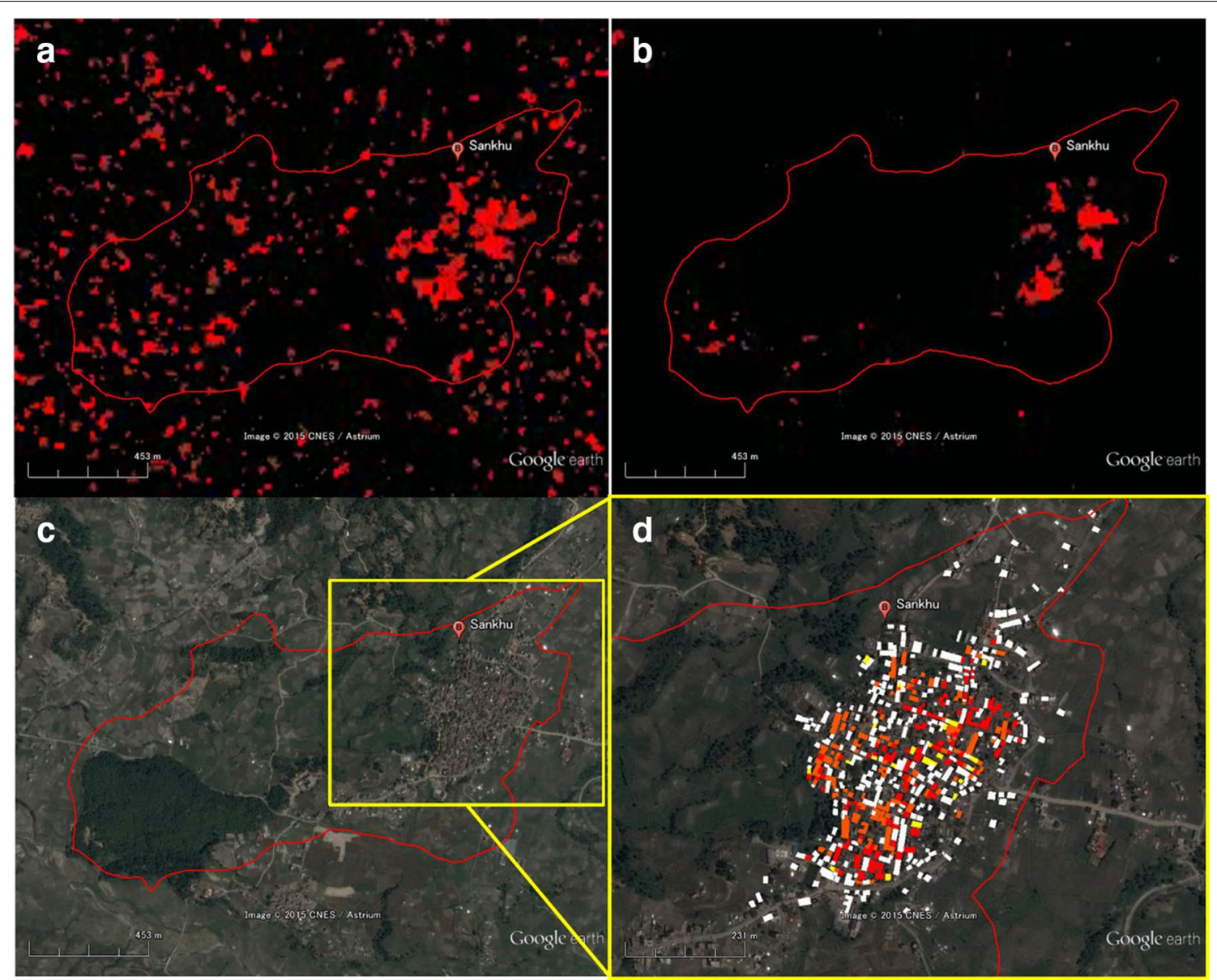

Fig. 4 a Area with $\Delta Y_{\mathrm{HH}} \geq 0.2$ obtained in Sankhu. A red polygon represents the municipality border, Pukhulacchi. b Area with $\Delta Y_{(H H, H V)} \geq 0.2$ and coherence filter. c Google Earth image. d Building damage survey result obtained in Sankhu. Red Grade 5. Orange Grade 4. Yellow Grade 2-3. White Grade $0-1$

the accuracy of detection of the damaged area decreased from 42.1 to $15.5 \%$ for damage level $\geq 4$ (see bold italics figures in Table 3). This is explained by the severe threshold level of 0.4, which could miss detection of damaged areas. The threshold level of $0.1-0.3$ is appropriate for detecting damaged areas. The final detection maps are shown in Figs. 3f, 4b, and 5b.

A distinct decrease in coherence was observed for several iconic buildings in central Kathmandu, which were completely destroyed. These included temples in Durbar Square and the Dharahara tower (Fig. 6ad). Field experiments also demonstrated that the damaged areas of many dilapidated buildings observed in Bhaktapur corresponded to the areas where $\Delta \gamma_{(\mathrm{HH}}$, HV) decreased.

\section{Madhyapur Thimi and Gangabu}

A decrease in coherence was observed in Kausaltar of the Madhyapur Thimi area near the Tribhuvan International Airport in Kathmandu (Fig. 6e, f). Few damaged buildings were observed in the field experiment in this area. Moreover, road damage due to liquefaction was observed in the area. This is consistent with the results obtained by Kobayashi et al. (2011). 


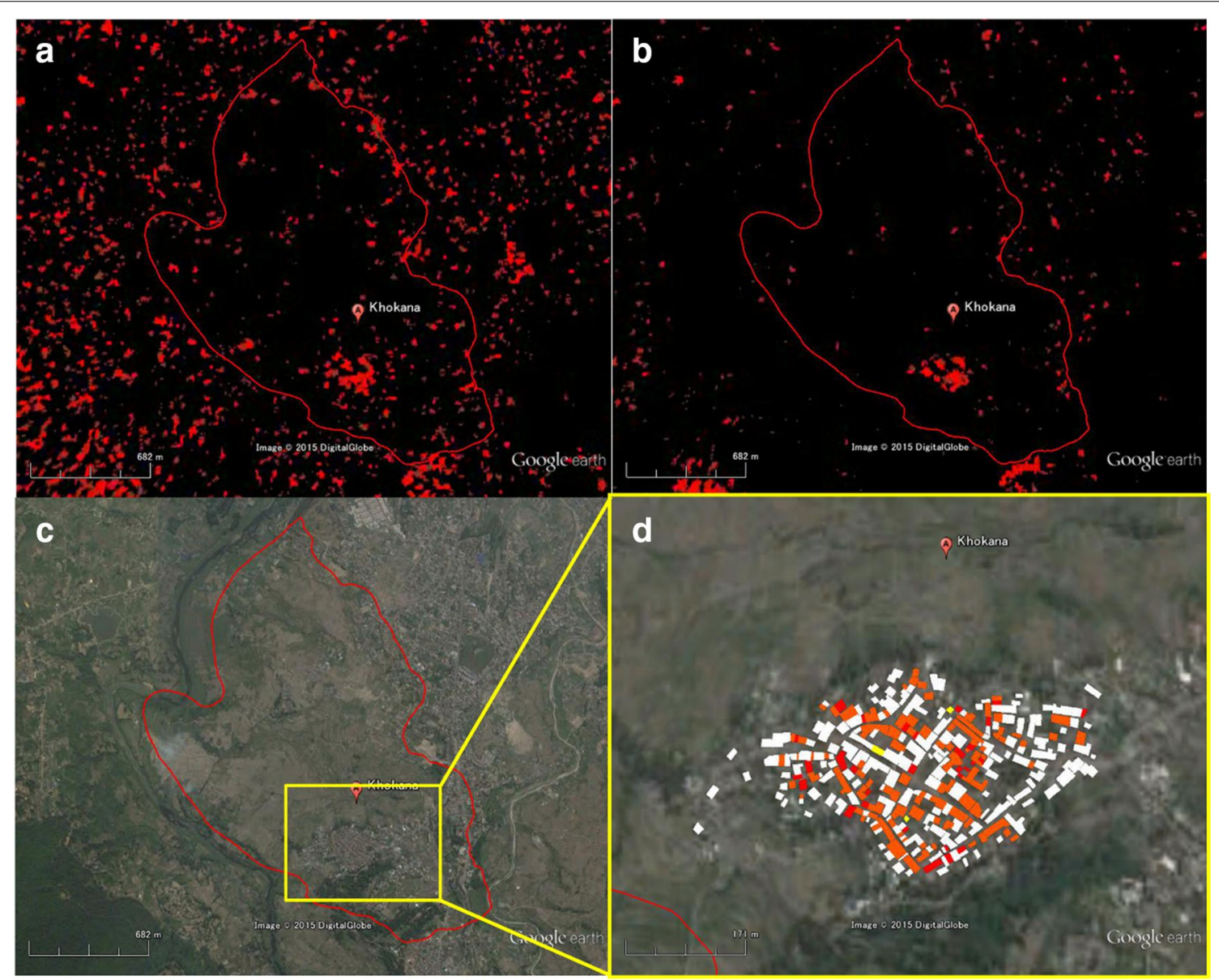

Fig. 5 a Area with $\Delta Y_{H H} \geq 0.2$ obtained in Khokana. A red polygon represents the municipality border, Khokana. b Area with $\Delta Y_{(H H, H V)} \geq 0.2$, and coherence filter. c Google Earth image. d Building damage survey result obtained in Khokana. Red Grade 5. Orange Grade 4. Yellow Grade 2-3. White Grade $0-1$

Table 2 Classification accuracy: polarization and coherence filter on or off

\begin{tabular}{|c|c|c|c|c|c|c|c|c|c|c|}
\hline & \multirow[t]{2}{*}{ Coherence filter } & & \multicolumn{4}{|l|}{ Khokana } & \multicolumn{4}{|l|}{ Sankhu } \\
\hline & & & Prod. acc. & User acc. & Ave. & Overall accuracy & Prod. acc. & User acc. & Ave. & Overall accuracy \\
\hline \multirow[t]{4}{*}{$\Delta \gamma_{\mathrm{HH}}$} & Off & Damage & 51.8 & 6.7 & 29.3 & 95.0 & 54.8 & 10.6 & 32.7 & 87.9 \\
\hline & & Damage-free & 95.3 & 99.7 & 97.5 & & 88.7 & 98.8 & 93.7 & \\
\hline & On & Damage & 45.6 & 10.5 & 28.0 & 97.1 & 39.6 & 20.7 & 30.2 & 94.9 \\
\hline & & Damage-free & 97.4 & 99.6 & 98.5 & & 96.3 & 98.5 & 97.4 & \\
\hline \multirow[t]{2}{*}{$\Delta Y_{\mathrm{HV}}$} & On & Damage & 47.1 & 12.1 & 29.6 & 97.4 & 31.7 & 16.8 & 24.2 & 94.6 \\
\hline & & Damage-free & 97.7 & 99.6 & 98.7 & & 96.2 & 98.3 & 97.2 & \\
\hline \multirow[t]{2}{*}{$\Delta Y_{(H H, H V)}$} & On & Damage & 50.3 & 20.0 & 35.1 & 98.3 & 31.7 & 22.4 & 27.1 & 95.8 \\
\hline & & Damage-free & 98.7 & 99.7 & 99.2 & & 97.3 & 98.3 & 97.8 & \\
\hline
\end{tabular}


Table 3 Classification accuracy: damage level and $\Delta \boldsymbol{Y}_{(\mathrm{HH}, \mathrm{HV})}$ threshold level

\begin{tabular}{|c|c|c|c|c|c|c|c|c|c|c|}
\hline \multirow[t]{2}{*}{ Damage level } & \multirow[t]{2}{*}{$\Delta Y_{(\mathrm{HH}, \mathrm{HV})}$ threshold } & & \multicolumn{4}{|l|}{ Khokana } & \multicolumn{4}{|l|}{ Sankhu } \\
\hline & & & Prod. acc. & User acc. & Ave. & Overall acc. & Prod. acc. & User acc. & Ave. & Overall acc. \\
\hline \multirow{8}{*}{$\begin{array}{l}\text { Case (1) damage level } \geq 0 \text { (all } \\
\text { buildings) }\end{array}$} & \multirow[t]{2}{*}{0.1} & $\mathrm{D}$ & 60.6 & 25.1 & 42.9 & 96.7 & 32.2 & 37.7 & 34.9 & 93.3 \\
\hline & & DF & 97.3 & 99.4 & 98.3 & & 96.9 & 96.0 & 96.5 & \\
\hline & \multirow[t]{2}{*}{0.2} & $\mathrm{D}$ & 38.7 & 34.9 & 36.8 & 98.0 & 26.1 & 43.0 & 34.5 & 94.0 \\
\hline & & DF & 98.9 & 99.1 & 99.0 & & 98.0 & 95.8 & 96.9 & \\
\hline & \multirow[t]{2}{*}{0.3} & D & 18.0 & 52.0 & 35.0 & 98.5 & 16.6 & 52.2 & 34.4 & 94.5 \\
\hline & & DF & 99.8 & 98.8 & 99.3 & & 99.1 & 95.3 & 97.2 & \\
\hline & \multirow[t]{2}{*}{0.4} & $\mathrm{D}$ & 6.5 & 56.0 & 31.2 & 98.5 & 6.2 & 50.6 & 28.4 & 94.4 \\
\hline & & DF & 99.9 & 98.6 & 99.3 & & 99.6 & 94.8 & 97.2 & \\
\hline \multirow{8}{*}{$\begin{array}{l}\text { Case (2) damage level } \geq 4 \text { (heavy } \\
\text { structural damage) }\end{array}$} & \multirow[t]{2}{*}{0.1} & $\mathrm{D}$ & 71.2 & 13.0 & 42.1 & 96.7 & 37.0 & 18.6 & 27.8 & 94.6 \\
\hline & & DF & 96.8 & 99.8 & 98.3 & & 96.1 & 98.4 & 97.2 & \\
\hline & \multirow[t]{2}{*}{0.2} & D & 50.3 & 20.0 & 35.1 & 98.3 & 31.7 & 22.4 & 27.1 & 95.8 \\
\hline & & DF & 98.7 & 99.7 & 99.2 & & 97.3 & 98.3 & 97.8 & \\
\hline & \multirow[t]{2}{*}{0.3} & D & 26.7 & 34.0 & 30.4 & 99.2 & 21.5 & 29.0 & 25.2 & 96.9 \\
\hline & & DF & 99.7 & 99.5 & 99.6 & & 98.7 & 98.1 & 98.4 & \\
\hline & \multirow[t]{2}{*}{0.4} & D & 11.5 & 44.0 & 27.8 & 99.3 & 6.9 & 24.1 & 15.5 & 97.3 \\
\hline & & DF & 99.9 & 99.4 & 99.7 & & 99.5 & 97.8 & 98.6 & \\
\hline \multirow{8}{*}{$\begin{array}{l}\text { Case (3) damage level }=5 \text { (total } \\
\text { collapse) }\end{array}$} & \multirow[t]{2}{*}{0.1} & D & 66.7 & 1.5 & 34.1 & 96.4 & 40.8 & 8.1 & 24.5 & 95.1 \\
\hline & & DF & 96.5 & 100.0 & 98.2 & & 95.6 & 99.4 & 97.5 & \\
\hline & \multirow[t]{2}{*}{0.2} & D & 45.8 & 2.3 & 24.1 & 98.3 & 35.0 & 9.8 & 22.4 & 96.3 \\
\hline & & DF & 98.4 & 100.0 & 99.2 & & 96.9 & 99.4 & 98.1 & \\
\hline & \multirow[t]{2}{*}{0.3} & D & 20.8 & 3.3 & 12.1 & 99.4 & 21.7 & 11.6 & 16.6 & 97.7 \\
\hline & & DF & 99.5 & 99.9 & 99.7 & & 98.4 & 99.3 & 98.8 & \\
\hline & \multirow[t]{2}{*}{0.4} & $D$ & 16.7 & 8.0 & 12.3 & 99.8 & 4.2 & 5.8 & 5.0 & 98.4 \\
\hline & & DF & 99.8 & 99.9 & 99.9 & & 99.4 & 99.1 & 99.2 & \\
\hline
\end{tabular}

$D$ damage, $D F$ damage-free

Building damage surveys were conducted in every house in Gangabu of Kathmandu by Kusunoki (2015), and severe building damage was reported. However, the $\Delta \gamma_{(\mathrm{HH}, \mathrm{HV})}$ map shows an inappreciable decrease in coherence (Fig. 7b). Figure 8 shows the $\gamma_{(\mathrm{HH}, \mathrm{HV})}$ image for Khokana, Sankhu, and Gangabu with value $\geq 0.5$ obtained before the disaster $\left(\gamma_{\text {pre }}\right)$. As expected, higher coherence values were observed for Khonaka and Sankhu. In contrast, a lower coherence value was observed for Gangabu. Unlike Khokana, Sankhu, and several iconic buildings, the density of the buildings was very high in Gangabu, and the spaces between buildings were limited. This may have prevented double-bounce scattering in the Gangabu area and lead to the lower coherence observed in this area.
Misclassification was observed for some forest stands in the mountainous area (Fig. 7c, d). The Google image indicated that the forest density was low, and this might have induced the higher coherence value in the forest area.

The classification accuracy was lower (27.1-35.1\%) for damaged areas and higher (97.8-99.2 \%) for the damagefree areas in $\Delta \gamma_{(\mathrm{HH}, \mathrm{HV})}$. This is because urban areas do not always show a higher coherence value, as shown in Fig. 8df. However, the higher classification accuracy of the damage-free area helps to detect the damaged urban area.

\section{Conclusions}

The interferometric SAR coherence-change technique with a coherence filter, and $\mathrm{HH}$ and $\mathrm{HV}$ polarization, was 


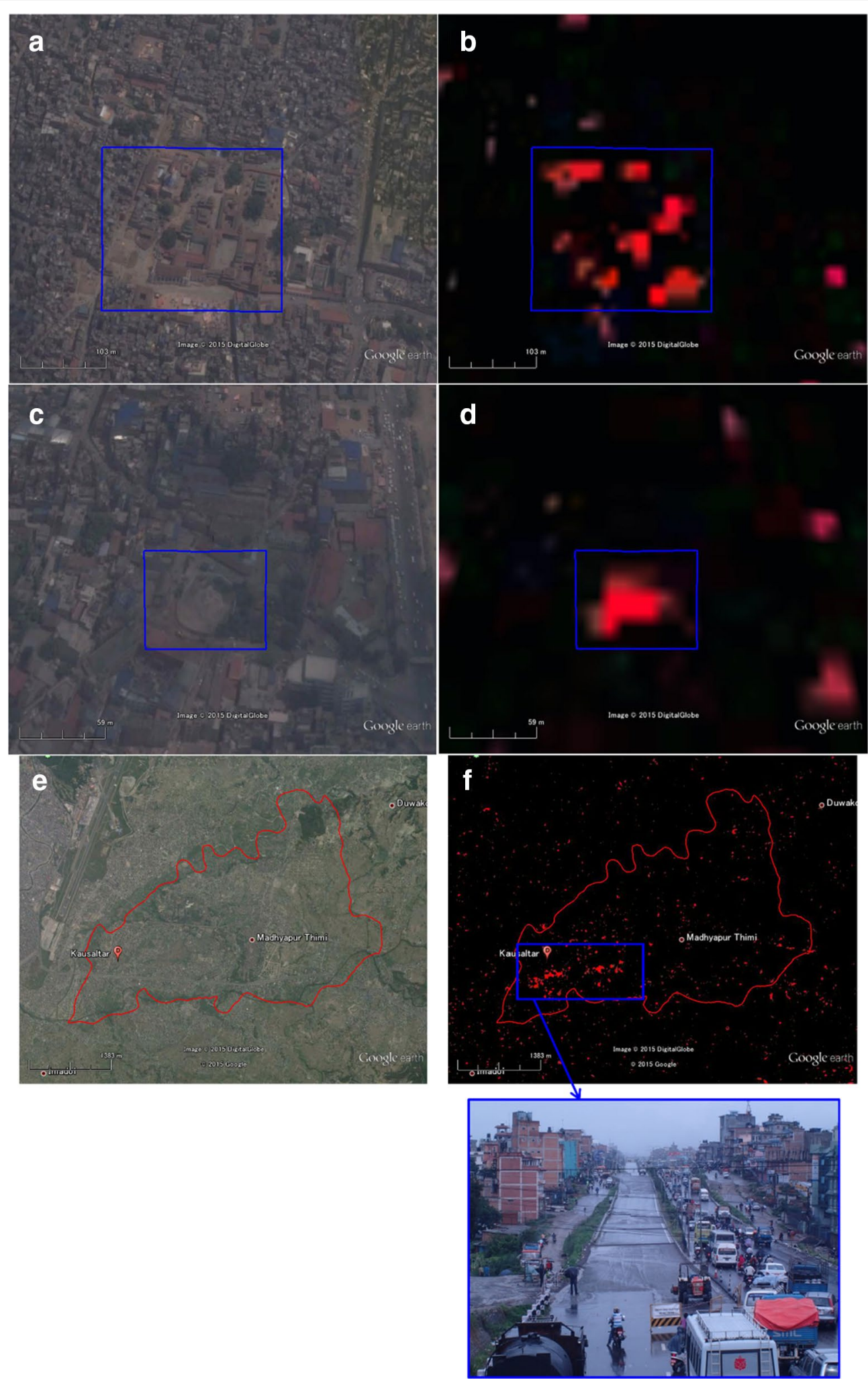

Fig. 6 a, b Durbar Square, c, d Dharahara tower, e, f Kausaltar of Madhyapur Thimi area. Left raw Google Earth image. Right raw Area with $\Delta Y_{(H H, H V)} \geq 0.2$, and coherence filter 

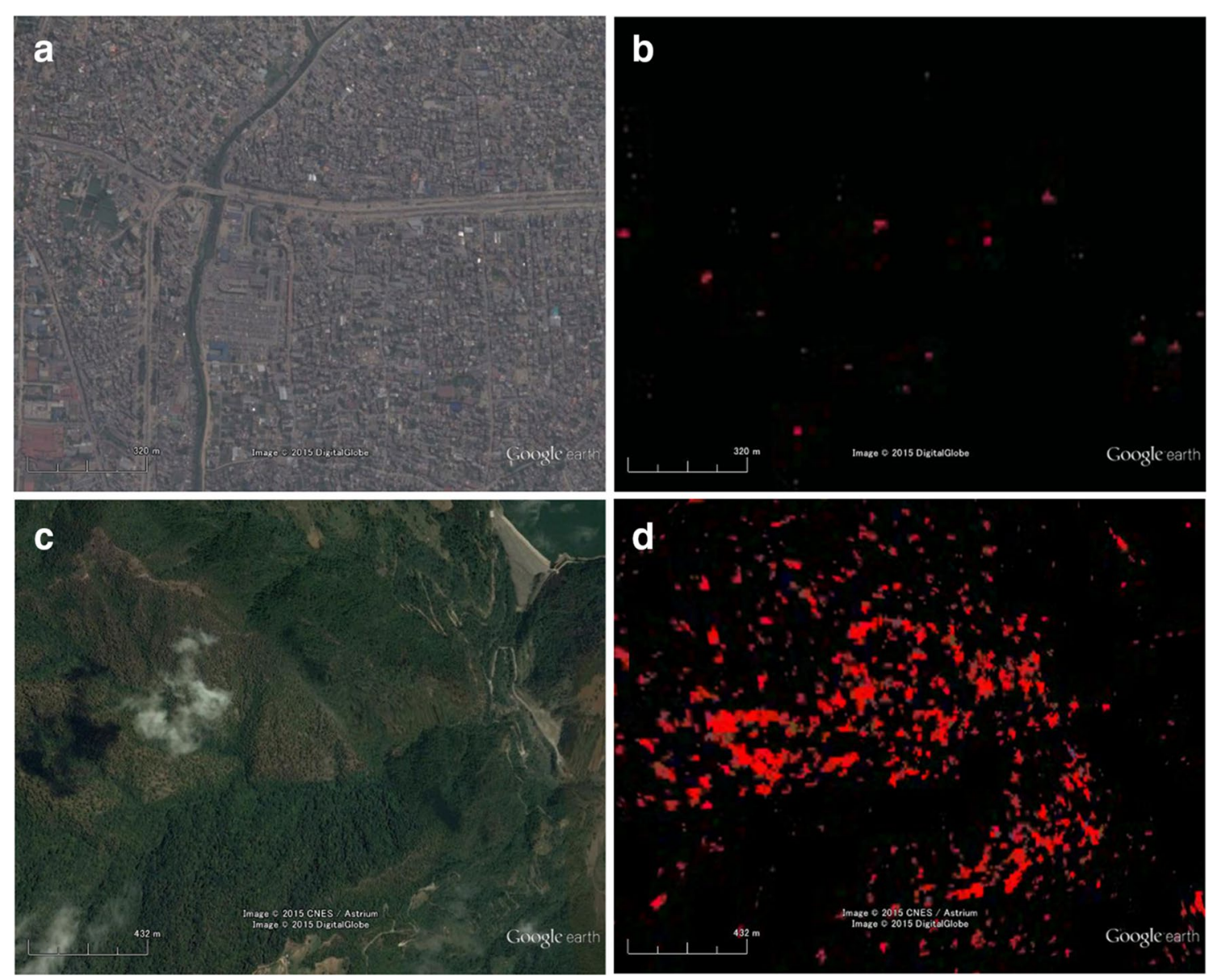

Fig. 7 a, b Gangabu, c, d a mountainous area. Left raw Google Earth image. Right raw Area with $\Delta \gamma_{(H H, H V)} \geq 0.2$, and coherence filter

used to detect damaged buildings in the area affected by the 2015 Gorkha Earthquake. Building damage surveys were conducted in every house to evaluate the detection accuracy in Khokana and Sankhu. The damaged parts of the urban area were adequately detected using coherence-change values obtained before the disaster $\left(\gamma_{\text {pre }}\right)$ and during the disaster $\left(\gamma_{\text {int }}\right)$. A coherence filter improved the overall accuracy from about 2.1-7.0\% of $\Delta \gamma_{\mathrm{HH}}$. The incorporation of $\mathrm{HV}$ polarization marginally improved the accuracy from 0.9 to $1.2 \%$. Heavy structural damage (damage level $\geq 4$ ) seems to be detected by this method.
A threshold level of $0.1-0.3$ is appropriate to detect the damaged areas in this case. It was confirmed that road damage due to liquefaction was also observed using the interferometric SAR coherence-change technique. The classification accuracy was lower (27.1-35.1\%) for damaged areas and higher (97.8-99.2 \%) for damagefree areas in $\Delta y_{(\mathrm{HH}, \mathrm{HV})}$. However, the higher classification accuracy for areas that were damage-free helped to detect the damaged urban areas in a wide-scale image, using this technique immediately after the occurrence of a disaster. 


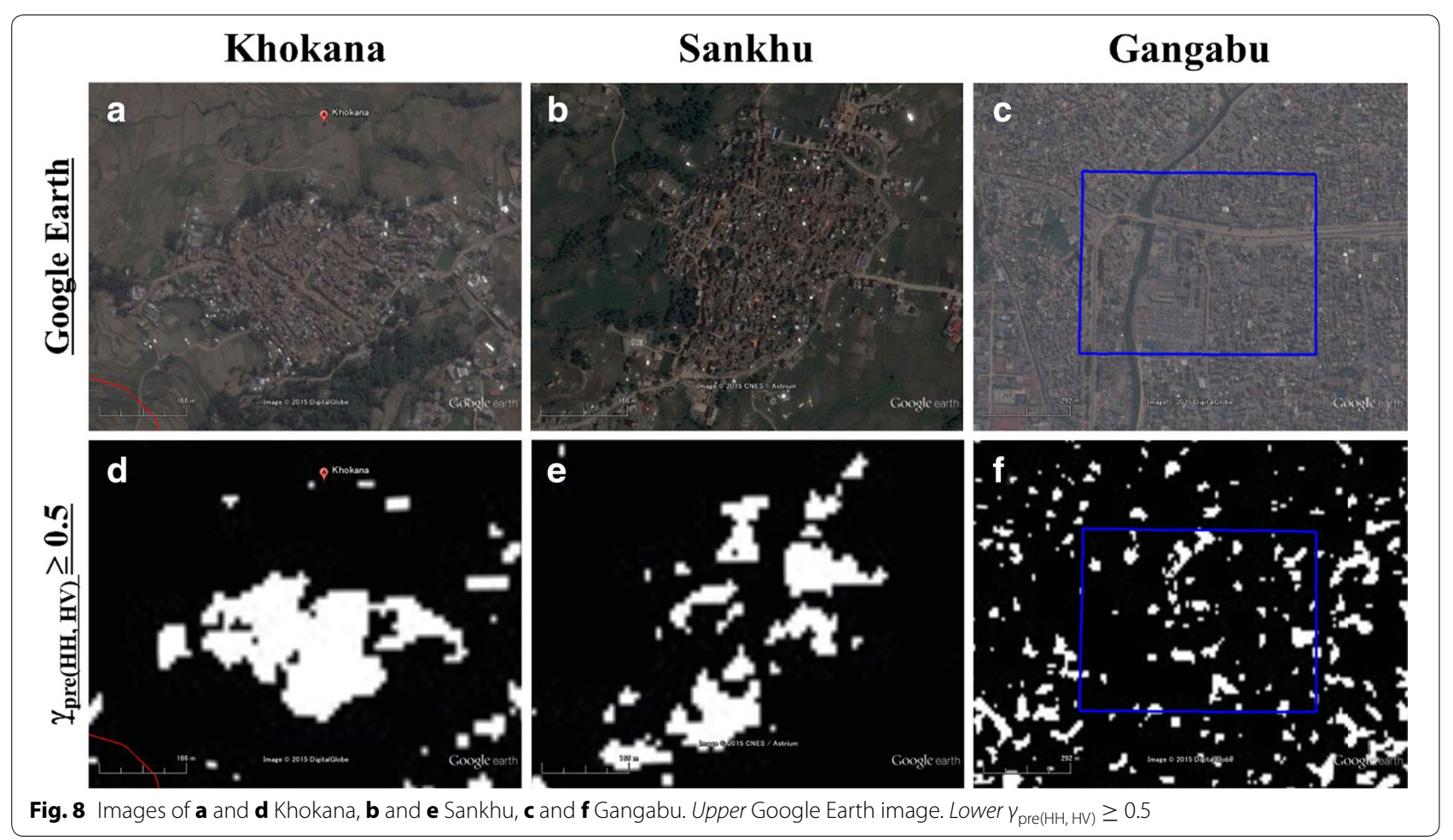

\section{Abbreviations}

EMS-98: The European Macroseismic Scale; PALSAR: phased array type L-band synthetic aperture radar; SAR: synthetic aperture radar.

\section{Authors' contributions}

MW analyzed the SAR data and drafted the manuscript. RT joined the field experiment and offered numerous suggestions regarding the SAR analysis. TO joined the field experiment and evaluated the building damage. He also offered numerous suggestions regarding the building damage. HF offered numerous suggestions regarding the building damage. $\mathrm{CY}$ offered numerous suggestions regarding the difference in coherence analysis. NT and SS offered numerous suggestions about the whole experiment and ALOS-2. All authors read and approved the final manuscript.

\section{Author details}

1 JAXA/EORC, 2-1-1 Sengen, Tsukuba, Ibaraki 305-8505, Japan. ${ }^{2}$ Present Address: School of Science and Engineering, Tokyo Denki University, Ishizaka, Hatoyama, Hiki, Saitama 350-0394, Japan. ${ }^{3}$ Research Center for Reinforcement of Resilient Function, National Research Institute for Earth Science and Disaster Resilience (NIED), 3-1 Tennodai, Tsukuba, Ibaraki 305-0006, Japan. ${ }^{4}$ Graduate School of Agricultural Science, Tohoku University, 1-1 Amamiya-machi, Tsutsumidori, Aoba-ku, Sendai, Miyagi 981-8555, Japan. ${ }^{5}$ Satellite Applications and Operations Center (SAOC), Japan Aerospace Exploration Agency (JAXA), Ochanomizu Sola City, 4-6 Kandasurugadai, Chiyoda-ku, Tokyo 101-8008, Japan.

\section{Acknowledgements}

This work was (partially) supported by the Council for Science, Technology, and Innovation (CSTI) through the Cross-ministerial Strategic Innovation Promotion Program (SIP), titled "Enhancement of societal resiliency against natural disasters" (Funding agency: JST).

\section{Competing interests}

The authors declare that they have no competing interests.

Received: 25 December 2015 Accepted: 11 July 2016 Published online: 22 July 2016

\section{References}

Arciniegas GA, Bijker W, Kerle N, Tolpekin VA (2007) Coherence- and amplitude-based analysis of seismogenic damage in Bam, Iran, using ENVISAT ASAR data. IEEE Trans Geosci Remote Sens 45(6):1571-1581

Chen S, Sato M (2013) Tsunami damage investigation of built-up areas using multitemporal spaceborne full polarimetric SAR images. IEEE Trans Geosci Remote Sens 51 (4):1985-1997. doi:10.1109/TGRS.2012.2210050

Geospatial Information Authority of Japan (2015) The 2015 Nepal earthquake: crustal deformation detected by ALOS-2 data. http://www.gsi.go.jp/cais/ topic150429-index-e.html. Accessed 23 June 2016

Grünthal G (ed) (1998) European Macroseismic Scale 1998. In: Cahiers du Centre Européen de Géodynamique et de Séismologique, vol 15, Centre Européen de Géodynamique et de Séismologie, Luxembourg, 101 pp Kimura H (2008) Radar polarization orientation shifts in built-up areas. IEEE Trans Geosci Remote Sens Lett 5(2):217-221

Kobayashi T, Tobita M, Koarai M, Otoi K, Nakano T (2011) Liquefaction area associated with the 2011 off the Pacific coast of Tohoku earthquake inferred from interferometric SAR coherence change. J Geosp Inf Auth Jpn 122:143-151 (in Japanese)

Kobayashi T, Morishita Y, Yarai H (2015) Detailed crustal deformation and fault rupture of the 2015 Gorkha earthquake, Nepal, revealed from ScanSARbased interferograms of ALOS-2. Earth Planets Space 67:201

Kusunoki K (2015) Building disaster prevention. Kenchiku Bosai 454:16-19 (in Japanese, http://www.kenchiku-bosai.or.jp/backnumber/201511.htm?ref=446)

Li X, Guo H, Zhang L, Chen X, Liang L (2012) A new approach to collapsed building extraction using RADARSAT-2 polarimetric SAR imagery. IEEE Trans Geosci Remote Sens Lett 9(4):677-681. doi:10.1109/ LGRS.2011.2178392

Lucas R, Armston J, Fairfax R, Fensham R, Accad A, Carreiras J, Kelley J, Bunting P, Clewley D, Bray S, Metcalfe D, Dwyer J, Bowen M, Eyre T, Laidlaw M, Shimada M (2010) An evaluation of the ALOS PALSAR L-band backscatter-above ground biomass relationship Queensland, Australia: impacts of surface moisture condition and vegetation structure. IEEE J Sel Topics Appl Earth Obs Remote Sens 3:576-593

Matsuoka M, Yamazaki F (2004) Use of satellite SAR intensity imagery for detecting building areas damaged due to earthquakes. Earthq Spectra 2(3):975-994 
Natsuaki R, Nagai H, Motohka T, Ohki M, Watanabe M, Thapa RB, Tadono T, Shimada M, Suzuki S (2016) SAR interferometry using ALOS-2 PALSAR-2 data for the Mw 7.8 Gorkha, Nepal earthquake. Earth Planets Space 68:15. doi:10.1186/s40623-016-0394-4

Ohsumi T, Imai H, Inoue H, Aoi S, Fujiwara H (2016) Investigation of damage in and around Kathmandu Valley related to the 2015 Gorkha, Nepal Earthquake, Report of the National Research Institute for Earth Science and Disaster, Prevention, No.404; March, 2016, ISSN0917-057X, pp 1-54

Story M, Congalton R (1986) Accuracy assessment-a user's perspective. Photogramm Eng Remote Sens 52(3):397-399

Tamura M, El-Gharbawi T (2015) Mapping damage in Ishinomaki city due to the 2011 Tohoku Earthquake using. In: SAR coherence change, proceedings of the 58th spring conference of the remote sensing society of Japan, pp 29-30 (in Japanese)

US Geological Survey (2015) M7.8 - 34 km ESE of Lamjung, Nepal. http:// earthquake.usgs.gov/earthquakes/eventpage/us20002926. Accessed 23 June 2016

Warren SG, Eastman RMA (2007) Survey of changes in cloud cover and cloud types over land from surface observations, 1971-96. J Clim 20:717-738. doi:10.1175/JCLI4031.1
Watanabe M, Motohka T, Miyagi Y, Yonezawa C, Shimada M (2012) Analysis of urban areas affected by the 2011 off the Pacific coast of Tohoku earthquake and tsunami with L-band SAR full-polarimetric mode. IEEE Trans Geosci Remote Sens Lett 9(3):472-476

Watanabe M, Motohka T, Shiraishi T, Thapa RB, Yonezawa C, Nakamura N, Shimada M (2015) Multi-temporal fluctuations in L-band backscatter from a japanese forest. IEEE Trans Geosci Remote Sens 53(11):5799-5813

Way JB, Paris J, Kasischke E, Slaughter C, Viereck L, Christensen N, Dobson MC, Ulaby FT, Richards J, Milne A, Sieber A, Ahern FJ, Simonett D, Hoffer R, Imhoff M, Weber J (1990) The effect of changing environmental conditions on microwave signatures of forest ecosystems Preliminary results of the March 1988 Alaskan aircraft SAR experiment. Int J Remote Sens 11:1119-1144. doi:10.1080/01431169008955084

Yonezawa C, Takeuchi S (2001) Decorrelation of SAR data by urban damages caused by the 1995 Hyogoken-nanbu earthquake. Int J Remote Sens 22(8):1585-1600

\section{Submit your manuscript to a SpringerOpen ${ }^{\circ}$ journal and benefit from:}

- Convenient online submission

- Rigorous peer review

- Immediate publication on acceptance

- Open access: articles freely available online

- High visibility within the field

- Retaining the copyright to your article 